\title{
Healthcare Waste, Pandemic Covid-19: A Case of India
}

\author{
Dinesh Kumar†, Sukesh Trikha and Ranju Anthony \\ Center of Social Medicine \& Community Health, Jawaharlal Nehru University, New Delhi-110067, India \\ Corresponding author: Dinesh Kumar; dr.dinesh999@yahoo.com
}

Nat. Env. \& Poll. Tech.

Website: www.neptjournal.com

Received: 12-02-2021

Revised: 20-04-2021

Accepted: 30-04-2021

\section{Key Words:}

Healthcare waste

Covid-19 pandemic

Biomedical waste management PPE

\section{ABSTRACT}

The present pandemic, while causing economic slowdown and global panic, also generated healthcare waste in unprecedented amounts across the globe, due to mass screenings/diagnosing/treatment. This paper aims to explore the prospects of the current and future challenges with respect to the risk to human health due to environmental contamination with the healthcare waste generated as a result of and caused by the Covid-19 pandemic in the Indian context. Peer-reviewed literature with respect to healthcare waste generation during the pandemic, its burden, challenges, and policies promulgated during the pandemic and their implications for the future was searched on various databases like PubMed, Google Scholar, and Science Direct and reviewed. Many research studies and international reports have demonstrated that the quantity of biomedical waste has increased in the times of the Covid-19 pandemic across the globe. Additionally, the danger of general waste getting contaminated has also multiplied, in part due to increased quarantine facilities and home quarantines, along with hospitals managing Covid-19 patients and also due to inadequate segregation at the point of generation of such waste, which is a major concern in itself. The occupational exposure of this increased waste to hospital and municipal waste collection workers has also increased, though World Health Organization (WHO) declines having any evidence of transmission of coronavirus while handling healthcare waste. Enough policies existed before the pandemic and few newer guidelines are also issued to address various additional aspects, which are to be implemented to manage the healthcare waste, minimize threats to the environment and human health. Cleaner, greener waste management facilities, the inclusion of bio-disaster in disaster management, the social impact of waste management policies, and waste reduction are to be prioritized.

\section{INTRODUCTION}

Around late December, China, in one of its provinces, reported a cluster of pneumonia-like cases, which were later confirmed and diagnosed as 'Covid-19' cases on $7^{\text {th }}$ January 2020 (Holshue et al. 2020). Thereafter, the newly diagnosed disease 'Covid-19' was declared a global health emergency by WHO on $31^{\text {st }}$ January 2020 (Yu et al. 2020), which has put healthcare delivery systems under severe strain globally. Barely, in the past three decades, many pathogens like HIV/ novel-influenza have caused pandemics and novel-coronavirus is the latest in this series (Tandon 2020), but may not be the last. Subsequent to the Severe Acute Respiratory Syndrome (SARS-CoV-1) and Middle East Respiratory Syndrome (MERS-CoV-2), epidemics in the recent past have caused not only economic predicament in the affected countries but have also led to a global trepidation (Holshue et al. 2020). Similarly, and uniquely, the current pandemic of Covid-19 has posed perilous challenges and raised questions afresh with respect to biomedical waste management to different stakeholders all around the globe and specifically in India, namely, the authorities (policymakers), hospital managements, urban local bodies, common biomedical waste treatment facilities, Panchayati Raj Institutions, and last but not the least, to the society at large.

The healthcare waste generation is an obvious outcome in the process of mass screening, diagnosing and treatment of diseases, especially in the epidemic/pandemic, albeit in huge amounts. The improper /unscientific disposal of healthcare waste generated from healthcare facilities poses a serious threat to the environment and human health. Keeping these in view, the healthcare waste is defined as "any waste which is generated during the diagnosis, treatment or immunization of human beings or animals or research activities pertaining thereto or in the production or testing of biological or in health camps, including the categories mentioned in Schedule 1 of Biomedical Waste Management (BMWM) rules, 2016" (CPCB 2016). Furthermore, the Ministry of Environment, Forest and Climate Change (MoEFCC) revised the BMWM rules 1998 in 2016, "to improve the collection, segregation, processing, treatment and disposal of biomedical waste, in an environmentally appropriate manner, to reduce the generation of biomedical waste and its impact on environment thereof" (CPCB 2014, 2016). Over and above that National 
Green Tribunal adjudicated that "Unscientific disposal of bio-medical waste had the potential of serious diseases such as Gastrointestinal infection, Respiratory infection, Eye infection, Genital infection, Skin infection, Anthrax, Meningitis, AIDS, Hemorrhagic fevers, Septicemias, Viral Hepatitis type A, Viral Hepatitis type B and C, etc. Such unscientific disposal also causes environmental pollution leading to the unpleasant smell, growth and multiplication of vectors like insects, rodents, and worms, and may lead to the transmission of diseases like typhoid, cholera, hepatitis, and AIDS through injuries from syringes and needles contaminated with various communicable diseases" (CPCB 2014, 2016).

This paper aims to explore the impact, burden and prospects of the current $\&$ future challenges with respect to the risk to human health due to environmental contamination with the healthcare waste generated as a result of and caused by the Covid-19 pandemic. Peer-reviewed literature with respect to healthcare waste generation during the pandemic, its burden, challenges, and management was searched on various databases like PubMed, Google Scholar, and Science Direct and reviewed for exploration.

\section{IMPACT AND BURDEN}

As per WHO (2020a), out of the total healthcare waste generated globally, $85 \%$ is general non-hazardous waste, whereas the remaining $15 \%$ is considered hazardous which could be infectious, toxic, and radioactive (WHO 2020b). Though, in the present pandemic, some studies depict that the major chunk of the healthcare waste $(75 \%)$ is general waste while the remaining $25 \%$ of the healthcare waste is hazardous infectious waste (Wang et al. 2020), which amounts to an increase in the hazardous category and is a serious concern in itself. Moreover, inadequate segregation of infectious and non-infectious healthcare waste, at the point of generation, could lead to a further increase in the quantum of infectious waste as a result of mixing of infectious healthcare waste with non-infectious waste. Therefore, in the wake of this ensuing pandemic, WHO emphasized ensuring good waste management practices, which will further help to prevent human to human transmission of Covid-19 (WHO 2020c).

Additionally, and obviously, due to the lockdown effect in view of the epidemic, recycling processes were also hampered (Zambrano-Monserrate et al. 2020). Studies are suggesting that discarded personal protective equipment (PPE) is problematic, as there is a considerable increase in healthcare waste with the use of these products. The PPE includes gloves, medical masks, goggles, or a face shield and gowns/coveralls for specific procedures. In addition, it includes respirators (N95 or FFP2 standard or equivalent) and aprons (WHO 2020d). But WHO cautioned that PPE is only one of the effective measures 'within a package of administrative and engineering control'. Further WHO stipulates that PPE should be used based on the risk of exposure and transmission dynamics of pathogen and the overuse of PPE may globally impact its supply chain. Another study forewarns that when millions of people using single-use masks or gloves, the amount of trash or biomedical waste generated would be substantial and the consequences thereof, would be far-reaching. The environmental impact of it will not only affect human health but also, will invariably affect the natural habitat and health of other species in the environment (WHO 2020e).

In the current times of pandemic, hazardous medical waste, which is mostly constituted of plastic is posing a great threat to the earth's ecosystem. Furthermore, the PPE which is mostly plastic and water-resistant material is often used for a single shift/day and gets discarded. This waste might often get disposed-off in landfills or oceans. The environmental impact of such waste would affect not only the health of the communities but also affect the natural habitat of other organisms \& species. A large amount of single-use discarded masks were found floating at 100-meter at a beach stretch (Sadat et al. 2020). Over and above that, general waste such as linen used tissues, and paper waste may also get contaminated. As one of the studies has suggested that these viruses could be found active on the surfaces even up to 72 hours (Ranjan et al. 2020). Irrevocably, the contaminated waste generated from laboratory facilities that are conducting diagnostic tests for Covid-19 patients, should be efficiently treated and stored within the laboratory till it is transported for final disposal (Maurya 2020). As a consequence, the problem of healthcare waste is actually compounding with an ever-increasing number of hospitals, nursing homes, and clinics (Hasaan et al. 2008), along with quarantine facilities/ laboratories in the present situation.

Presumably, the increase in the use of disposable materials has increased with the advancements in healthcare technology, which, has also led to enhancement of the problem (Sengodan 2014). But, in the present pandemic, the generation of biomedical waste has increased exponentially (Yu et al. 2020). The healthcare waste generation in Hubei province, increased by $(+370 \%)$ with a high proportion of plastic during the pandemic Covid-19 (Klemes et al. 2020). Also, it was estimated that hospitals were producing six times more healthcare waste (Ranjan et al. 2020). Asian Development Bank reported that many of the big Asian cities are producing tons of extra healthcare waste during the current pandemic, e.g., Manila 280 tons.day $^{-1}$, Jakarta 212 tons.day $^{-1}$, and Bangkok 210 tons.day $^{-1}$ (ADB 2020). Approximately, 550 tons of biomedical waste is generated in India on daily 
basis (Ranjan et al. 2020). Around 28\% of BMWs are left untreated and discarded improperly (Ramteke \& Sahu 2020). 181 tons of Covid-19 related waste was generated on the daily basis in October 2020 according to Central Pollution Control Board (CPCB) (CPCB 2020a). It was estimated that there was $3.41 \mathrm{~kg}$ per day of biomedical waste generation by each Covid-19 patient which is double the biomedical waste generated in pre-covid times. Additionally, the proportion of yellow category biomedical waste was 50.4 percent out of total biomedical waste (Thind et al. 2021). According to CPCB (2020a), Delhi alone generated 11 tons of Covid-19 related biomedical waste and 27 tons of non-covid related biomedical waste each day. "Quantity of household medical waste may reach up to $0.1 \%$ of the total mixed municipal solid waste stream" (Yordanova et al. 2014). The quantity of biomedical waste generated from households must have multiplied due to provisions like home quarantine, home isolation, and asymptomatic patients.

The healthcare waste generated finds its way to common biomedical waste treatment facilities or onsite treatment facilities for proper treatment and disposal. The patients suffering from Covid-19 are not restricted to hospitals only. A lot of people with mild symptoms around the globe are receiving home treatment, in addition to people in quarantine and isolation centers. Therefore, a lot of pathogen-contaminated waste is generated by the people quarantined in households. This pathogen-contaminated waste may probably contaminate the general waste and the waste collectors, if not segregated or handled appropriately. The WHO reports that till now there is no evidence of catching the coronavirus infection while handling the healthcare waste (WHO 2020). However, newer and newer studies are generating fresh evidence. Therefore, in the absence of evidence or till the evidence is generated, it is the stakeholder's responsibility to mitigate the risk of pandemic Covid-19, to the environment and human health.

Importantly, specified people are vulnerable to the risk posed by excessive healthcare waste, including waste collectors, cleaners, support staff, and health personnel (Sadat et al. 2020). The magnitude of occupational exposure to municipal and hospital waste collection workers has been the subject of many studies in the light of increased public concern about environmental and workers' health issues (Ferreira et al. 1999). The cleaning and maintenance services attendant may get contaminated via skin puncture, splash, infected surfaces, and additionally while cleaning and handling fecal material of the infected patient. Also, a person may get contaminated while handling the waste generated during patient care (CPCB 2020b). The WHO, in its interim guidelines on Water Sanitation and Hygiene (WASH) (WHO 2020), has categorically mentioned that the volume of infectious waste during the Covid-19 pandemic is expected to increase, especially through the use of PPE. Therefore, WHO emphasized the importance of enhancing the capacity of appropriate disposal of such infectious waste (WHO 2020).

Universal masking is becoming a norm in different parts of the world. Universal masking in health facilities is defined as "the requirement to wear a mask by all health workers and anyone entering the facility, no matter what activities are undertaken" (WHO 2020). However, wearing face masks in some Asian countries like Hong Kong, Japan, Taiwan, and South Korea is very common, partly because of air pollution and partly because of response to past outbreaks such as SARS and MERS outbreaks (Greenhalgh et al.2020). In East Asian countries face masks are even mandated by the governments (Javid et al. 2020). After social distancing (though physical distancing is apt), which is considered to be the most effective means of controlling the spread of the virus, the use of face masks is a popular non-pharmaceutical choice in the communities (Aggarwal et al. 2020). In addition to the discussion of whether masks should be used or not, WHO also stipulates that "for any type of mask, appropriate use and disposal are essential to ensure that they are as effective as possible and to avoid any increase in transmission" (WHO 2020). Additionally, the veterinary health facilities generate a considerable amount of biomedical waste which is similar in nature and quantum to biomedical waste generated by health facilities for humans. Therefore, the establishment of a joint surveillance system with a "one health approach" can have far-reaching benefits in current times.

Furthermore, the demand and supply cycles along with logistics/supply chain are severely impacted during the period of lockdown. According to WHO, the demand for the plastic product (PPE, Gloves, Masks, and Syringes, etc.), used as prevention, to protect the general public, health workers and patients, have arisen sharply. Additionally, due to the restricted movements driven scenario, the online delivery services demand increased, which has led to the increase in the use of plastic as a packaging material (Klemes et al. 2020). Even earlier, the management of plastic waste was a grave environmental issue. While now with the present pandemic, the possibility of pathogen-contaminated plastic has increased manifold, which ought to be treated as infectious hazardous waste and therefore, the quantum of waste generation in this pandemic has reached never before proportions, presumably.

\section{Wastewater}

It is of great significance to reduce the risk to the environment and public health through proper management of healthcare wastewater in times of the current pandemic. While dissem- 
inating guidelines for managing the Covid-19 biomedical waste generated from healthcare facilities/home care/isolation wards, CPCB has not done any significant revision in the guidelines for the treatment of wastewater discharged from such facilities. A large quantum of patients are asymptomatic and receiving care in the form of home care or home quarantine. While citing information provided by the Center for Disease Control (CDC) of USA, CPCB mentioned that 'the risk of coronavirus causing Covid-19 through sewage wastewater appears to be low' and therefore did not make any significant change in the guidelines for managing Covid-19 infected wastewater. But, the contact of hospital effluents with the aquatic ecosystem poses serious long-term threats to aquatic life (Syed et al. 2012).

There are studies that indicate that SARS-CoV-2 may infect the drainage systems as it is found active in hospital wastewater. Coronavirus has been found in the sewage sludge of an infected area (Ranjan et al. 2020). Also, SARS-CoV-2 has been cultured in a single stool sample (Wang et al. 2020). In quarantine or isolation centers including the home where suspected or confirmed cases are kept, fecal material should be considered as a biohazard and treated accordingly (WHO 2020). Presence of coronaviruses in the sewage system and stool samples may indicate the possibility of fecal-oral transmission of the virus. Therefore, such frameworks (fecal-oral transmission) are also being proposed for further research (Heller et al. 2012). If such a hypothesis is confirmed, other far-reaching dynamics will unfold which will impact pandemic and control strategies (Heller et al 2020). Therefore, it necessitates the careful disinfection, treatment, and disposal of healthcare wastewater.

Apart from the safe treatment and disposal, wastewater from healthcare facilities and communities could be analyzed for the presence of coronavirus in the wastewater or sewage sludge. Due to resource constraints, it is nearly impossible to do clinical testing of all the individuals. Also, stool samples for coronavirus may test positive even after the nasopharyngeal swab sample test negative. Additionally, studies have suggested that coronavirus may show more waves of the epidemic (Sundararaman 2020). In such scenarios of emergence and re-emergence of coronavirus, wastewater monitoring could be a viable option to assess the state of infection in a community (Kumar 2020).

\section{TREATMENT}

A study conducted by Singh and Prakash (2007) in India, revealed that the proportion of bio-medical waste in total general waste generated was comparatively high ranging from $12.5 \%$ to $69.3 \%$, which indicates inappropriate waste handling processes followed at the point of generation (Syed et al. 2012). Strangely, out of 2.7 lac identified health facilities, only 1.1 lac health facilities are authorized under BMW management rules 2016 so far. Therefore, State Pollution Control Boards/ Pollution Control Committees will have to make serious efforts to identify and appropriately manage this lacuna (CPCB 2020c). According to CPCB, a total of 198 Common Biomedical Waste Treatment Facilities (CBWTF) are operating in the country. Few states like Goa and Sikkim are devoid of any CBWTF. According to CPCB's annual report of 2018 (CPCB 2018), a total of 2,60,889 healthcare facilities are estimated to generate 608 MT biomedical waste per day, out of which only 528 MT is treated and disposed of through common biomedical waste treatment facilities. According to the National Green Tribunal, available capacity of incineration is $840 \mathrm{MT}$ per day and only 55 percent of cumulative incinerator capacity is being utilized.

The present available biomedical waste treatment facilities were designed and made operational for the quanta of waste generated in pre-Covid-19 conditions and are not geared up for conditions like the present pandemic, where there is a sudden and rapid increase in the quantities of healthcare waste. The healthcare waste generation in Wuhan, increased from 40 tons.day ${ }^{-1}$ to 240 tons.day $^{-1}$, during the peak of the pandemic. However, the available maximum incineration capacity for biomedical waste in Wuhan was 49 tons.day ${ }^{-1}$. Therefore, healthcare waste generation exceeded far more than the handling capacity of treatment facilities. In such conditions, the life cycle approach could provide guidance for the identification and use of the most suitable alternative for the environment (Klemes et al. 2020). The concepts like plastic footprints and plastic waste footprints are introduced as a measure of the burden of plastic on the environment (Klemes et al. 2020). It is becoming very crucial for the governments to find a solution soon enough for the disposal of this increased healthcare waste as treatment facilities are limited with further limited capacities (Sadat et al. 2020).

\section{POLICIES}

The management of healthcare waste received little attention in South East Asian countries until the last millennium. With the outbreak of SARS in 2002, many countries reviewed their healthcare waste management system, which was further catalyzed by the Avian flu (H5N1) outbreak (Kuhling \& Pieper 2012). International agencies like WHO, CDC of USA, and Public Health of England have come up with additional guidelines for biomedical waste management generated during the current pandemic. Preventively, enough guidelines around the globe have advocated for the use of PPE/ single-use masks, and scientific management and disposal of 
these used items, which can minimize the unforeseen impacts on human health and the environment (Klemes et al. 2020).

The Bio-medical waste management \& handling rules 2016, under Environment Protection Act 1986 stipulates that "it is the responsibility of every hospital, clinic, nursing home, dispensary, veterinary institutions, animal house, and pathological laboratories \& blood banks to ensure that such waste is handled without any adverse effect to human health and environment" (CPCB 2017). Further, BMW rules also stipulate that it is the responsibility of the occupier to ensure that generated biomedical waste is treated and disposed of within 48 hours (CPCB 2020d). CPCB is the implementing agency for the implementation of BMWM rules in India. CPCB in India has issued guidelines for handling, treatment, and disposal of waste generated during treatment/diagnosis/ quarantine of Covid-19 patients, in addition to the existing Biomedical Waste Management guidelines (BMWM \& Handling Rules 2016) keeping in mind the current challenges posed by the pandemic. It has prescribed responsibilities of different stakeholders such as Health facilities, Common Biomedical waste treatment facilities, Urban Local Bodies, State Pollution Control Boards/Pollution Control Committees, Quarantine Camps/homes, and isolation facilities for proper handling \& management of healthcare waste generated from healthcare activities (CPCB 2020e).

Some of the notable additions to existing BMW management rules 2016 concerning Covid-19 are;

a. Healthcare facilities having isolation wards need to keep color-coded bins labeled as "Covid-19 Waste" with a foot-operated lid and a double layer bag (2 bags) that should be used for the collection of waste.

b. Bins having Covid-19 waste could be directly lifted from isolation wards to Common Biomedical Waste Treatment Facilities (CBWTF).

c. A separate record of Covid-19 waste is to be maintained on daily basis.

d. Dedicated trolleys and collection bins should be used in isolation wards and these vehicles should be sanitized with 1 percent Sodium Hypochlorite solution after each trip.

e. Opening of any Covid care facility or sample collection laboratories must be reported to SPCB/PCC and CBMTF. Also, these facilities need to get registered on the mobile application "COVID19BMW" and update the daily generation of BMW.

f. Feces from Covid-19 confirmed cases must be treated as biomedical waste and must be handled accordingly.

g. Used PPE such as goggles, face shield, splash-proof apron, plastic coverall, hazmat suit, nitrile gloves should be collected into red bags. Used masks, semi-plastic coveralls, shoe-cover, and disposable gowns should be collected into yellow bags. Also, used disposable items, leftover food, plate, glass, masks, and tissues of Covid-19 patients must be collected in yellow bins.

h. Urban local bodies need to provide yellow-colored bags to collect infected waste from isolation wards/homes/ quarantine camps.

i. The person taking care of home care/isolation wards/ quarantine camps must hand over biomedical waste collected in yellow bags to CBMWTF or ULBs.

j. Used masks of persons not infected by Covid-19 must be kept for 72 hours in a paper bag and are advisable to cut the mask before final disposal. Used masks or PPEs by infected or asymptomatic patients along with other infected waste generated during home care or home quarantine should be collected in different yellow bags and bins.

k. To minimize the waste, non-disposable items must be used and dry \& wet solid waste bags must be handed over to ULB's collector on daily basis.

1. BMWM in remote and rural areas devoid of any CBMWTF must be done through deep burial pits. In case of an increase in the quantity of biomedical waste beyond the capacity of existing treatment facilities, industrial incinerators may be used to dispose of the Covid-19 related biomedical waste safely.

Further, the person dealing with soiled clothes, beddings, and towels of Covid-19 patients should wear appropriate PPE before touching it which includes gloves, goggles, or face shield for eye protection, long-sleeved fluid-resistant gown, or an apron with boots or closed shoes. Hand hygiene must be maintained after the removal of these items. MoEFCC in Biomedical waste management rules stipulates that biomedical waste generated from households shall be segregated as per these rules in separate bags and shall be handed over to waste collectors. Urban Local Bodies shall have a tie-up with CBMWTF for the safe disposal of such waste in a prescribed manner. However, with the fast spread of coronavirus disease, challenges are getting intense with the safe disposal of biomedical waste management (CPCB 2020f).

\section{CHALLENGES}

\section{Challenges in Urban Areas}

Most of the secondary and tertiary level healthcare facilities in India are located in urban areas which include Community Health Centers (CHCs), District Hospitals, Medical Colleges, 
and Private health facilities. These facilities contribute to the generation of a major chunk of biomedical waste. In addition, a large chunk of the healthcare services is provided by informal healthcare workers both in urban and rural areas. These providers are not a direct part of the health services system in India. However, they are present in huge numbers and generate a large amount of biomedical waste in various forms. These health providers or facilities are not authorized or recognized by the health service system or with pollution control authorities. Therefore, biomedical waste generated by them is not treated or disposed of in a scientific manner. The facility for biomedical waste disposal and treatment through CBMWTF is located in urban areas or near the urban areas and is invariably shared between two or three districts. But notably, these facilities are designed for limited capacities and operations in a steady-state manner. With the addition of newer and temporary health facilities, quarantine camps, and isolation centers, these disposal facilities would definitely be under pressure. Enormous human, material, and infrastructural resources would be required for the safe and scientific disposal of biomedical waste as per the guidelines mentioned above for its disposal.

\section{Challenges in Rural Areas}

The majority of the Indian population still lives in rural areas. The requisite infrastructure of waste management viz. segregation, storage, collection, treatment, and disposal is lacking in rural areas. Informal health providers in rural areas also generate some quantity of biomedical waste in the form of needles, syringes, pathological and pharmaceutical waste. While, the quantity of biomedical waste from primary level facilities is low, but explicit guidelines are required for environmentally appropriate waste disposal. In rural areas, home isolation, or home care scenarios, persons dealing with Covid-19 suspected, asymptomatic, or confirmed patients are at risk of contracting coronavirus infection. A lot of infected generals and biomedical waste will be generated during such care. This waste would be treated as domestic hazardous waste and must be treated according to BMWM rules (CPCB 2017).

Recent guidelines or revisions to BMWM rules have established provisions for urban areas by defining the responsibilities of ULBs, while rural areas have been left out. The majority of the Indian population resides in villages; a lot of hazardous biomedical waste would be generated in rural areas in such situations. Who will be responsible for the dissemination of the information regarding yellow bin category waste? Who will provide yellow bags and who will guide villagers about standards of deep burial pit? Inadequate and improper biomedical waste and infected general waste management may catalyze the spread of infection.

\section{FUTURE OUTLOOK}

The WHO in its interim guidelines on WASH recommended that additional waste treatment capacity may need to be created, keeping in mind the increased use of disposal items like PPE during the Covid-19 pandemic. Preferable methods should include alternative treatment technologies such as autoclaving or high-temperature burn incinerators. Also, their sustained operation needs to be ensured (WHO 2020). The need is to develop waste management systems that incorporate a clean, green way of disposal.

Current disaster management systems are focused narrowly on natural calamities like earthquakes, tsunamis and flood, etc. Explicit decision-making tools are needed to be focused on waste management planning for special conditions like pandemic Covid-19 (Klemes et al. 2020). A detailed planning for bio-disaster response needs to be included in disaster management policy, though a chapter is added in draft National Disaster plan.

The experiences of Wuhan in management of excessive healthcare waste with application of reverse logistical models could be a potential solution. These models are focused on reverse flow in a supply chain. The ultimate aim is to maximize the value recovery from end of use \& end of life products through reuse, remanufacturing, recycling and energy recovery. Such models could provide quantitative and managerial support for effective management of biomedical waste (Yu et al. 2020). Furthermore, establishment of temporary waste transit centers and temporary waste treatment centers for treatment of excessive biomedical waste from temporary health facilities could be a viable option. Treated waste then could be sent to final waste disposal centers. However, selection of appropriate location in such scenarios would be the most important step of the whole process ( $\mathrm{Yu}$ et al. 2020). The focus of such measures is to balance the trade-off between environmental risk related to management of medical waste and economic performance.

Under solid waste management rules 2016, it is necessary to have a district environment plan to be operated by district committee (as a part of part of District Planning Committee under Article $243 \mathrm{ZD}$ ). In the current times of pandemic such plan may be extended to block and village levels to effectively monitor and guide biomedical waste disposal practices at these echelons. NGT (2020) has flagged the issues pertaining to household generation and management of biomedical waste. It highlighted that there is a need for further revisions in these guidelines to cover all the aspects and incorporate not merely institutions, but also households and dealing with the situations where facilities like incinerators are not available. Any unmindful deep burial without adequate safeguard can adversely affect the ground water and pose danger to health 
and safety of people (CPCB 2016). In techno-economic assessments of disaster responses, social factors need to find their space. The impacts on societies must be the concern and disaster responses should be designed accordingly. For the society at large, waste prevention/reduction should be at highest priority in all the policies, especially in healthcare waste management policies.

\section{KEY MESSAGE}

The current outbreak of the Covid-19 pandemic has led to a substantial increase in Biomedical waste (BMW) generation. Context-specific policy guided BMW management is critical for effective control of Covid-19 pandemic in urban \& rural areas of India.

\section{REFERENCES}

Aggarwal, N., Dwarakanathan, V., Gautam, N. and Ray, A. 2020. Facemasks for prevention of viral respiratory infections in community settings: a systematic review and meta-analysis. Indian J. Pub. Health, 64(6): 192.

Asian Development Bank (ADB). 2020. Managing Infectious Medical Waste During the COVID-19 Pandemic, 2020. Available from: https:// www.adb.org/sites/default/files/publication/578771/managing-medical-waste-covid19.pdf. Accessed 21 June 2020.

Central Pollution Control Board (CPCB). 2014. Biomedical Waste Management; An Overview, 2014. Available from: http://www.cpcbenvis.nic. in/envis_newsletter/BMW\%20Newsletter.pdf. Accessed 23 June 2020.

Central Pollution Control Board (CPCB). 2016. Biomedical Waste Management Rules; 2016. New Delhi.

Central Pollution Control Board (CPCB). 2017. Biomedical Waste Management Rules; 2016 (amended). Available from: http://www.cpcbenvis. nic.in/pdf/BMW_Amended_10.05.2019.pdf. Accessed 15 June 2020.

Central Pollution Control Board (CPCB). 2018. Annual Report 2017-18. Ministry of Environment \& Forests, GOI.

Central Pollution Control Board (CPCB). 2020b. Guidelines for Handling, Treatment, and Disposal of Waste Generated during Treatment/Diagnosis/ Quarantine of COVID-19 Patients - Revision 1, 2020. Available from: https://hspcb.gov.in/content/BMW/covid19/BMW-GUIDELINES-COVID2.pdf. Accessed 16 June 2020.

Central Pollution Control Board (CPCB). 2020c. Scientific Disposal of Bio-Medical Waste Arising Out of COVID-19 Treatment- Compliance of BMW Rules, 2016. Available from: https://hspcb.gov.in/content/ BMW/covid19/NGT_Order_covid_28.04.2020.pdf. Accessed 16 June 2020

Central Pollution Control Board (CPCB). 2020d. Guidelines for Handling, Treatment, and Disposal of Waste Generated during Treatment/ Diagnosis/ Quarantine of COVID-19 Patients - Reg, 2020. Available from: https://hspcb.gov.in/content/BMW/covid19/BMW-GUIDELINES-COVID1.pdf. Accessed 16 June 2020.

Central Pollution Control Board (CPCB). 2020e. Guidelines for Handling, Treatment, and Disposal of Waste Generated during Treatment/ Diagnosis/ Quarantine of COVID-19 Patients- Revision 3, 2020. Available from: https://cpcb.nic.in/openpdffile.php?id=TGF0ZXN0RmlsZS8yOTdfMTU5MjE0NzcwMF9tZWRpYXBob3RvMzA3NDgucGRm. Accessed 15 June 2020.

Central Pollution Control Board (CPCB). 2020f. Guidelines for Handling, Treatment, and Disposal of Waste Generated During Treatment/Diagnosis/ Quarantine of COVID-19 Patients - Revision 2, 2020. Available from: http://www.cpcbenvis.nic.in/pdf/BMW-GUIDELINES-COVID_1.pdf. Accessed 15 June 2020.
Central Pollution Control Board 2020a. Public Notice to HCFs and CBWTFs Regarding Handling, Collection, Transportation, and Disposal of Bio-Medical Waste Generated from Covid-19 affected Persons, 2020. Available from: https://hspcb.gov.in/content/BMW/covid19/ HSPCB_Adv_Corona_Guidelines.pdf. Accessed 2020 June 22.

Ferreira, J.A., Tambellini, A.T., da Silva, C.L.P. and Guimarães, M.A.A. 1999. Hepatitis B morbidity in municipal and hospital waste collection workers in the city of Rio de Janeiro. Infect. Control Hosp. Epidemiol., 20(9): 591-592.

Greenhalgh, T., Schmid, M.B., Czypionka, T., Bassler, D. and Gruer, L. 2020. Face masks for the public during the covid-19 crisis. Br. Med. J., 369: m1435.

Hasaan, M.M., Ahmed, S.A., Rahman, K.A. and Biswas, T.K. 2008. The pattern of medical waste management: an existing scenario in Dhaka city, Bangladesh. BMC Pub. Health, 8(1): 1-10.

Heller, L., Mota, C.R. and Greco, D.B. 2020. COVID-19 faecal-oral transmission: are we asking the right questions? Sci. Tot. Environ., 729: 138919.

Holshue, M.L., DeBolt, C., Lindquist, S., Lofy, K.H., Wiesman, J., Bruce, H., Spitters, C., Ericson, K., Wilkerson, S., Tural, A. and Diaz, G. 2020. The first case of the 2019 novel coronavirus in the United States. N. Engl. J. Med., 382: 929-936.

Javid, B., Weekes, M.P. and Matheson, N.J. 2020. Covid-19: Should the public wear face masks? Br. Med. J., 369: m144

Joint COVID-19 Taskforce. Second joint statement of the IPHA, IAPSM, and IAE- Public health approach for COVID-19 pandemic control in India. Indian Journal of Public Health 2020, 64: S84-6.

Klemes, J.J., Van Fan, Y., Tan, R.R. and Jiang, P. 2020. Minimizing the present and future plastic waste, energy, and environmental footprints related to COVID-19. Renew. Sustain. Energy Rev., 127: 109883.

Kuhling, J.G. and Pieper, U. 2012. Management of healthcare waste: developments in Southeast Asia in the twenty-first century. Waste Manage. Res., 30(9_suppl): 100-104.

Kumar, M. 2020. Wastewater monitoring and public health surveillance of SARS-CoV-2. Indian J. Pub. Health, 64(6): 247-8.

Maurya, D.T., Sapkal, G., Yadav, P.D., Belani, S.K.M., Shete, A. and Gupta, N. 2020. Biorisk assessment for infrastructure \& biosafety requirements for the laboratories providing coronavirus SARS-CoV-2/(COVID-19) diagnosis. Indian J. Med. Res., 151(2-3): 172.

NGT. 2020. Before The National Green Tribunal Principal Bench, New Delhi. In reply to Scientific Disposal of Bio-Medical Waste arising out of Covid-19 treatment- Compliance of BMW Rules 2016. Available from: https://greentribunal.gov.in/gen_pdf_test.php?filepath. Accessed on 20 April 2021.

Ramteke, S., \& Sahu, B. L. 2020. Novel coronavirus disease 2019 (COVID-19) pandemic: considerations for the biomedical waste sector in India. Case Stud. Chem. Environ. Eng., 2: 100029.

Ranjan, M.R., Tripathi, A. and Sharma, G. 2020. Medical waste generation during COVID-19 (SARS-CoV-2) pandemic and its management: an Indian perspective. Asian J. Environ. Sci., pp.10-15.

Sadat, S., Rawtani, D. and Hussain, C.M. 2020. The environmental perspective of COVID-19. Sci. Tota. Environ., 128: 138870.

Sengodan, V.C. 2014. Segregation of biomedical waste in the South Indian tertiary care hospital. J Nat. Sci. Biol. Med., 5(2): 378

Singh, S. and Prakash, V. 2007. Toxic environmental releases from medical waste incineration: a review. Environmental Monitoring and Assessment,132(1): 67-81.

Sundararaman, T. 2020. Health systems preparedness for COVID-19 pandemic. Indian J. Pub. Health, 64(6): 91.

Syed, E.H., Mutahara, M. and Rahman, M. 2012. Medical waste management (MWM) in Dhaka, Bangladesh: It's a review. Home Health Care Manag. Pract., 24(3): 140-145.

Tandon, P.N. 2020. COVID-19: Impact on health of people \& wealth of nations. Indian J. Med. Res., 151(2-3): 121. 
Thind, S.P., Sareen, A., Singh, D.D., Singh, S. and John, S. 2021. The compromising situation of India's bio-medical waste incineration units during the pandemic outbreak of COVID-19: Associated environmental-health impacts and mitigation measures. Environ. Pollut., 1; 276: 116621.

Wang, J., Shen, J., Ye, D., Yan, X., Zhang, Y., Yang, W., Li, X., Wang, J., Zhang, L. and Pan, L. 2020. Disinfection technology of hospital wastes and wastewater: suggestions for disinfection strategy during coronavirus Disease 2019 (COVID-19) pandemic in China. Environmental Pollution, 128: 114665

Wang, J., Shen, J., Ye, D., Yan, X., Zhang, Y., Yang, W., Li, X., Wang, J., Zhang, L. and Pan, L. 2020. Disinfection technology of hospital wastes and wastewater: Suggestions for disinfection strategy during coronavirus Disease 2019 (COVID-19) pandemic in China. Environ. Pollut., 128: 114665.

World Health Organization (WHO) 2020b. Advice on the Use of Masks in The Context of COVID-19: Interim Guidance, 2020.

World Health Organization (WHO). 2020a. Available from: https://www. who.int/emergencies/diseases/novel-coronavirus-2019?gclid=Cj0KCQjw6PD3BRDPARIsAN8pHuG27VS4NA4r-K2nRRqvntrcY3CvZYpkPmv2HSBNovUAXZ0F8jiXjGYaAqihEALw_wcB. Accessed 1 July 2020.

World Health Organization (WHO). 2020c. Rational Use of Personal
Protective Equipment (PPE) for Coronavirus Disease (COVID-19): Interim Guidance, 19 March 2020.

World Health Organization (WHO). 2020d. Water, Sanitation, Hygiene and Waste Management for COVID-19: Technical Brief, 03 March 2020.

World Health Organization (WHO). 2020e. Situation Report-11 Novel Coronavirus (2019-ncov), 31 January 2020. Available from: https://www.who.int/docs/default-source/coronaviruse/situation-reports/20200131-sitrep-11-ncov.pdf?sfvrsn=de7c0f7_4. Accessed 23 June 2020

World Health Organization (WHO). 2020f. Health Care Waste. Available from: https://www.who.int/news-room/fact-sheets/detail/health-carewaste. Accessed 23 June 2020.

Yordanova, D., Angelova, S., Kyoseva, V. and Dombalov, I. 2014. Household medical waste-threat to the environment and human health. Journal of Chemical Technology \& Metallurgy, 49(2).

Yu, H., Sun, X., Solvang, W.D. and Zhao, X. 2020. Reverse logistics network design for effective management of medical waste in epidemic outbreaks: insights from the coronavirus disease 2019 (COVID-19) outbreak in Wuhan (China). Int. J. Environ. Res. Public Health, 17(5): 1770.

Zambrano-Monserrate, M.A., Ruano, M.A. and Sanchez-Alcalde, L. 2020. Indirect effects of COVID-19 on the environment. Sci. Tot. Environ., 728: 138813 